\title{
Disentangling the effects of shrubs and herbivores on tree regeneration in a dry Chaco forest (Argentina)
}

\author{
Andrés Tálamo • Alicia H. Barchuk • \\ Lucas A. Garibaldi · Carlos E. Trucco • \\ Silvana Cardozo $\cdot$ Federico Mohr
}

Received: 5 April 2014 / Accepted: 7 February 2015

(C) Springer-Verlag Berlin Heidelberg 2015

\begin{abstract}
Successful persistence of dry forests depends on tree regeneration, which depends on a balance of complex biotic interactions. In particular, the relative importance and interactive effects of shrubs and herbivores on tree regeneration are unclear. In a manipulative study, we investigated if thornless shrubs have a direct net effect, an indirect positive effect mediated by livestock, and/or an indirect negative effect mediated by small vertebrates on tree regeneration of two key species of Chaco forest
\end{abstract}

Communicated by Juan J Armesto.

Electronic supplementary material The online version of this article (doi:10.1007/s00442-015-3269-7) contains supplementary material, which is available to authorized users.

\section{A. Tálamo $(\bowtie)$}

Instituto de Bio y Geociencias del Noroeste Argentino (IBIGEO), Consejo Nacional de Investigaciones Científicas y Técnicas (CONICET) and Universidad Nacional de Salta (UNSa),

Mendoza 2, CP 4400 Salta, Salta Capital, Argentina

e-mail: andrestalamo@gmail.com

\section{A. H. Barchuk}

Facultad de Ciencias Agropecuarias, Universidad de Córdoba,

Córdoba, Argentina

\section{A. Garibaldi}

Sede Andina, Universidad Nacional de Río Negro (UNRN) and Consejo Nacional de Investigaciones Científicas y Técnicas (CONICET), Mitre 630, CP 8400 San Carlos de Bariloche, Río Negro, Argentina

\section{E. Trucco}

Maestría en Turismo Sustentable, Facultad de Ciencias Naturales, Universidad Nacional de Salta (UNSa), Salta, Argentina

S. Cardozo · F. Mohr

Facultad de Ciencias Naturales, Universidad Nacional de Salta

(UNSa), Salta, Argentina
(Argentina). In a spatial association study, we also explored the existence of net positive interactions from thorny and thornless shrubs. The number of Schinopsis lorentzii seedlings was highest under artificial shade with native herbivores and livestock excluded. Even excluding livestock, no seedlings were found with natural conditions (native herbivores present with natural shade or direct sunlight) at the end of the experiment. Surprisingly, seedling recruitment was not enhanced under thornless shrubs, because there was a complementary positive effect of shade and interference. Moreover, thornless shrubs had neither positive nor negative effects on regeneration of $S$. lorentzii. Regeneration of Aspidosperma quebracho-blanco was minimal in all treatments. In agreement with the experiment, spatial distributions of saplings of both tree species were independent of thornless shrubs, but positively associated with thorny shrubs. Our results suggest that in general thornless shrubs may have a negligible effect and thorny shrubs a net positive effect on tree regeneration in dry forests. These findings provide a conceptual framework for testing the impact of biotic interactions on seedling recruitment in other dry forests.

Keywords Livestock $\cdot$ Facilitation $\cdot$ Herbivory $\cdot$ Nurse plants $\cdot$ Spatial association

\section{Introduction}

Emergence and establishment are critical phases for tree populations in arid and semi-arid areas because most seedlings die due to high temperatures, lack of water and nutrients, and/or high rate of herbivory (Harper 1977; McAuliffe 1986; Kitajima and Fenner 2000). However, shrubs may facilitate the regeneration of trees by providing 
suitable microhabitats for the survival of seedlings. Shrubs may mitigate the harsh physical conditions, provide shade, create nutrient islands, improve hydric conditions (Callaway 1995; Carrillo-Garcia et al. 2000; Flores and Jurado 2003; Michalet 2006), and protect seedlings from herbivory (Flores and Jurado 2003; Brooker et al. 2008). Identifying the factors affecting tree regeneration, and evaluating their positive or negative effects are fundamental steps towards an effective restoration strategy in arid forests.

Both theoretical and empirical studies suggest that positive (facilitation) and negative (interference) interactions among plants act simultaneously (Callaway and Walker 1997; Holmgren et al. 1997; Maestre et al. 2003; Graff et al. 2007). Direct facilitation among plants takes place when, for example, a nurse plant (e.g., a shrub) improves microclimate conditions or resource availability for another plant (a target plant, e.g., a tree seedling) (Bertness and Callaway 1994; Flores and Jurado 2003; Michalet 2006; Brooker et al. 2008). On the other hand, the nurse plant may also have direct negative effects, reducing germination, survival and growth rates of a target plant as a result of interference (Ridenour and Callaway 2001; Jensen et al. 2011; Peguero et al. 2012). In addition, these positive and negative effects may arise via indirect pathways. Indirect facilitation can take place when a third species interacts, for example, when a nurse plant negatively affects (via interference) the performance of the competing plant, indirectly benefiting the target plant (Cuesta et al. 2010; Prevosto et al. 2012). Another example of indirect facilitation, which is our study case, occurs when the target plant is associated with a nurse plant with low palatability and/or physical structures (spines, thorns, dense branching) that deter herbivores and therefore reduce their consumption rates, an interaction known as associational resistance (Callaway 1995; Baraza et al. 2006; Smit et al. 2006; Barbosa et al. 2009; Graff and Aguiar 2011). Nevertheless, the associational effect may be negative by increasing the likelihood of detection by, and/or vulnerability to, herbivores (associational susceptibility). The latter interaction is more likely with small animals (insects and small mammals), for example when a seedling shows lower performance as a result of herbivory of small animals that shelter in the nurse plant (Barbosa et al. 2009; Caccia et al. 2009; Chaneton et al. 2010; Orrock et al. 2010). Although the success of tree regeneration in forests is known to depend on the balance among these interactions (Online Resource 1), few studies have attempted to disentangle the direct and indirect effects of nurse plants on tree seedling establishment (GomezAparicio et al. 2008; Caccia et al. 2009).

Among the dry forests of Latin America, the dry Chaco has the largest extent of continuous forests and is of high conservation value (Dinerstein et al. 1995; Portillo-Quintero and Sanchez-Azofeifa 2010). A large part of this landscape is being drastically modified by agricultural expansion, mainly for soybean cultivation (Boletta et al. 2006; Gasparri and Grau 2009; Seghezzo et al. 2011). The two dominant tree species in the dry Chaco forest have a mesic origin. Aspidosperma quebracho-blanco Schlecht. (Apocynaceae) is sclerophyllous and evergreen and inhabits a wide precipitation gradient $(300-1,200 \mathrm{~mm})$, whereas Schinopsis lorentzii (Griseb.) Engl. (Anacardiaceae) is brevi-deciduous and has a more restricted precipitation gradient (Prado 1993). Both species have anemochorous dispersion and their seeds are affected by fungi and have little vigor (Alzugaray et al. 2007). Shrubs are an important component of the dry Chaco, both in terms of basal area and density (Tálamo and Caziani 2003), and likely provide favorable microsites for tree seedlings. Shrubs can generate significant amounts of organic matter, and reduce the temperature and radiation under their canopies (Paez and Marco 2000). For example, in the arid Chaco (300-500 mm), the regeneration of A. quebracho-blanco depends on interactions of soil type and seasonal rainfall variation with nurse plants (Barchuk et al. 2005). For this reason, A. quebracho-blanco saplings are spatially associated with shrubs, mainly with evergreens (Barchuk et al. 2008). In the semiarid Chaco (700 mm), Capparis spp. (Capparaceae) shrubs are evergreen or semi-evergreen and therefore are potential nurse shrubs. In addition, although these shrubs are thornless, they are usually non-preferred by grazers (Catan and Degano 2007), thereby deterring livestock with the result of an indirect positive effect on neighboring plants. Even within protected areas, grazing of cattle and goats is frequent, which in this environment may contribute to modification of plant communities as a result of herbivory and trampling. However, the role of shrubs in tree regeneration has not been investigated in detail in this semiarid system, nor has the possible interactive effects of shrubs with herbivores.

In this study, we analyze the direct and indirect (consumer-mediated) influences of shrubs on the regeneration of the two dominant tree species of the dry Chaco $(S$. lorentzii and A. quebracho-blanco). We first assessed whether short-term regeneration of these two species is facilitated by thornless shrubs (Capparis sp.) and whether there is interaction with livestock (indirect positive effect) and native herbivores (indirect negative effect) using a field experiment. We then undertook a field survey in a grazed area in order to infer possible past net positive interactions by analyzing whether saplings of both tree species were spatially associated with thorny and thornless shrubs (possible nurse plants).

Because forest conditions in the dry Chaco are potentially stressful for the studied tree species (extremely high temperatures, up to $52{ }^{\circ} \mathrm{C}$ under canopy cover), we predicted that Capparis spp. shrubs would act as nurse plant 
and enhance seedling recruitment of both tree species studied. Regarding the association effects, we propose that the sign of this effect depends on the type of herbivore (livestock vs. small native herbivores). Given that Capparis spp. are not preferred by livestock (Catan and Degano 2007) and have a dense branching pattern, we predicted that Capparis spp. shrubs would deter livestock enhancing the recruitment of seedlings beneath shrub canopy. On the other hand, because shrubs may act as shelters for small native herbivores (Chaneton et al. 2010; Orrock et al. 2010), thus increasing the herbivory levels on seedlings, we predicted a negative effect of the shrubs in the presence of small native vertebrates. Finally, regarding the spatial patterns, we expect a positive spatial association between shrubs and saplings of both tree species if shrubs had a positive net effect.

\section{Materials and methods}

Study area

The study was conducted in the southwest area of Copo National Pak, province of Santiago del Estero, Argentina $\left(25^{\circ} 55^{\prime} \mathrm{S}, 62^{\circ} 0.5^{\prime} \mathrm{W}\right)$. The climate of the region is markedly seasonal, with $80 \%$ of the $700 \mathrm{~mm}$ annual rainfall occurring between October and March (wet season). The semideciduous thorn forest is dominated by $S$. lorentzii, A. quebracho-blanco and Ziziphus mistol (Rhamnaceae) (Tálamo and Caziani 2003). The understory contains not only thornless shrubs such as Capparis retusa, $C$. saliscifolia, $C$. tweediana, C. atamisquea (Capparaceae) and Achatocarpus praecox (Achatocarpaceae) but also numerous thorny shrubs like Acacia praecox (Fabaceae), A. furcatispina, Mimosa detinens (Fabaceae), Mimozyganthus carinatus (Fabaceae), Cercidium praecox (Fabaceae), Celtis pallida (Ulmaceae), Castela coccinea (Simaroubaceae), Maytenus spinosa (Celastraceae) and Schinus polygamus (Anacardiaceae) (Tálamo and Caziani 2003). In the study area, there are three small settlements of local people living mainly on small-scale livestock ranching with a stocking load of approximately 500 cattle and 100 goats grazing over $\sim 10,000$ ha.

\section{Experimental design}

We collected fruits of $S$. lorentzii (single seed indehiscent samara) and seeds of A. quebracho-blanco in good phytosanitary conditions. Each experimental unit consisted of 100 fruits of the first species and 100 seeds of the second species. The experiment was conducted separately for each tree species using a split-plot design with five blocks and repeated measures in time. Each block $(50 \times 100 \mathrm{~m})$ was divided into two main $50 \times 50 \mathrm{~m}$ plots (Online Resource 2 ), and randomly assigned the levels of "livestock" (Gr: grazed, or Ex: exclusion, using a seven-strand wire fence for exclusion). The exclosures were installed just before the fruits and seeds were sown. Within each main plot, six treatments (combinations of levels of the factors) were randomly assigned; two levels of "small native vertebrates exclusion" (C: caged or U: uncaged) and three levels of "shade" (Ss: shade of Capparis shrubs under tree canopy, Sa: artificial shade, and Su: sunlight) (Online Resource 2). Artificial shade was provided by means of green $2.5 \mathrm{~mm}$ nylon nets $\left(1 \mathrm{~m}^{2}\right.$ area, $40 \mathrm{~cm}$ above-ground), overlapped until light intensity was $80-90 \%$ of open sunlight. Circular 2-mm wire mesh cages were used to exclude small native vertebrates, which protected fruits and seeds from granivores (small rodents and birds), and seedlings from small herbivores (rabbits and brocket deer), but did not exclude small invertebrate herbivores. Given that two levels of the shade factor required open areas ( $\mathrm{Sa}$ and $\mathrm{Su}$ ), and vegetation could not be removed in a National Park, we used sites of old charcoal ovens as open sky areas, which provide gaps of $10-15 \mathrm{~m}$ diameter. An ancient method was used for oven construction. First, woody vegetation was cut. Then, the trunks and branches were stacked in the cut area and covered with mud to build the oven. These ovens were used in the 1950s and then abandoned. Because of the high temperatures that these charcoal ovens caused, the physical and chemical properties of the soil may have been modified. In order to control this source of variation, we replaced the soil in areas affected by charcoal ovens with soil $(50 \mathrm{~cm} \times 50 \mathrm{~cm} \times 20 \mathrm{~cm}$ deep $)$ from unaffected areas located within a few meters. The response variable analyzed in each experimental unit was the number of seedlings that emerged from 100 seeds or fruits sowed, recorded every 2 months from March 2007 to March 2008. Because individual seedlings were not marked, we did not measure seedling survival but instead recorded total number of observed seedlings (seedling abundance) as the response variable. We also measured seedling size (number of leaves). Sample size of the latter variable was too small for a statistical analysis; however, we report the general patterns observed.

To characterize microsite light conditions for tree seedlings, we measured light intensity under the different shade treatments. Measurements were taken between 10:00 and 15:00 hours for two consecutive sunny days. Photosynthetic photon flux density (PPFD) was recorded at $5 \mathrm{~cm}$ height above the soil level in the following experimental units: 48 open sky, 12 artificial shade, and 33 shrubs (Capparis spp.) using a Basic Quantum Meter (model BQM-S; Apogee Instruments, USA). The presence of shrubs significantly modified the light environment. Mean PPFD values were significantly higher in open sky plots compared 
to the artificially shaded and shrubs plots $\left(F_{2,90}=158.8\right.$, $P<0.0001,80-90 \%$ sunlight reduction). We did not detect difference in the PPFD values between artificial shade and shrub plots.

Spatial association of tree saplings with potential nurse shrubs

We delimited a $50 \times 50 \mathrm{~m}$ plot in a random location where we recorded $X$ (east-west) and $Y$ (north-south) coordinates of all woody individuals. We then divided the plot into $2.5 \times 2.5 \mathrm{~m}$ sub-units (matching the size of the shrub canopies). Therefore the initial grid had 400 sample units where we counted the number of shrubs and tree saplings $(\mathrm{DBH}<5 \mathrm{~cm})$ of both species.

\section{Data analysis}

The data of the field experiment were analyzed with generalized linear mixed-effect models for the influences of livestock exclusion (Ex or Gr), native vertebrate herbivores exclusion ( $\mathrm{C}$ or $\mathrm{U}$ ), shade ( $\mathrm{Ss}, \mathrm{Sa}$, or $\mathrm{Su}$ ), date (seven levels: each date), and all interactions on the number of seedlings of $S$. lorentzii using R software (v.2.15.1, lme4 package, lmer function; Bates et al. 2012; R Development Core Team 2012). A binomial error distribution and a logit link function were employed to model the number of seedlings from 100 fruits in each microsite (Zuur et al. 2009). The model considered that sampling dates were repeated measures of each micro-site, that micro-sites were nested within livestock exclosure plots, and that plots were nested within blocks (i.e., random intercept model of blocks, plots, and micro-sites; Fig. 2) (Zuur et al. 2009). Residuals of the model showed no temporal autocorrelation, and significance tests were performed using likelihood ratio tests (Zuur et al. 2009). Because of the extremely low recruitment of A. quebracho-blanco (see "Results"), no statistical analyses were performed on this species. Additionally, in order to assess the kind (positive or negative) and magnitude of shrubs direct and indirect effects on tree regeneration, we summarized effects as the differences in mean number of seedlings (from 100 seeds sowed) in respective treatment combinations, as follows:

1. Direct effect of shade, controlling the effect of native and domestic herbivores: $Y_{\mathrm{As}-\mathrm{C}-\mathrm{Ex}}-Y_{\mathrm{Su}-\mathrm{C}-\mathrm{Ex}}$. If artificial shade mitigates the stressful conditions, an increase in regeneration under the nylon net is expected (difference in means $>0$ ).

2. Direct effect of shrubs by interference, controlling the effect of native and domestic herbivores: $Y_{\mathrm{Ss}-\mathrm{C}-\mathrm{Ex}}{ }^{-}$ $Y_{\mathrm{As}-\mathrm{C}-\mathrm{Ex}}$. If there is interference between shrubs and seedlings, a decrease in regeneration under shrubs is expected (difference in means $<0$ ).

3. Net effect of shrubs, controlling the effect of native and domestic herbivores: $Y_{\mathrm{Ss}-\mathrm{C}-\mathrm{Ex}}-Y_{\mathrm{Su}-\mathrm{C}-\mathrm{Ex}}$. If the positive effect outweighs the negative effect, an increase in regeneration under shrubs is expected (difference in means $>0$ ).

4. Indirect effect of shrubs mediated by domestic herbivores: $\left(Y_{\mathrm{Ss}-\mathrm{U}}-Y_{\mathrm{Su}-\mathrm{U}}\right)_{\mathrm{Gr}}-\left(Y_{\mathrm{Ss}-\mathrm{U}}-Y_{\mathrm{Su}-\mathrm{U}}\right)_{\mathrm{Ex}}$. If shrubs deter domestic herbivores, a greater positive effect of shrubs in presence of cattle is expected (difference in means $>0$ ).

5. Indirect effect of shrubs mediated by native herbivores, controlling the effect of domestic herbivores: $\left(Y_{\mathrm{Ss}-}\right.$ $\left.\mathrm{U}^{-} Y_{\mathrm{Ss}-\mathrm{U}}\right)_{\mathrm{Ex}}-\left(Y_{\mathrm{Ss}-\mathrm{C}}-Y_{\mathrm{Su}-\mathrm{C}}\right)_{\mathrm{Ex}}$. If shrubs act as shelters for native herbivores, and affect the seedlings, a negative effect of shrubs in presence of native herbivores is expected (difference in means $<0$ ).

$Y$ was the mean number of seedlings (of 100 seeds) and the subscripts indicate the different combinations of treatments as was described in "Experimental design".

To assess the degree of association between the distribution of tree saplings (individuals with $\mathrm{dbh}<5 \mathrm{~cm}$ ) of each tree species (A. quebracho-blanco and S. lorentii) and the distribution of shrubs, we used the program SADIE (Spatial Analysis by Distance Indices) (Perry et al. 1996, 1999; Perry 1998). First, the program calculates a local cluster index $(v)$ of each unit in the grid for both data clusters (e.g., data for $S$. lorentzii and for shrubs). Then, using the spatial association method, which compares spatial patterns of both datasets, we estimated the contribution of each unit of the grid to the global correlation coefficient $\left(X_{\mathrm{p}}\right)$ between both sets of data analyzed. Positive $X_{\mathrm{p}}$ values show a positive spatial association. In contrast, negative $X_{\mathrm{p}}$ values show no match in spatial distribution patterns. Finally, using a resampling procedure with 10,000 iterations, we determined the probability (two-tailed) of finding values as extreme or more extreme than the value observed, enabling us to test the null hypothesis of no spatial association between groups. We conducted separate analyses for thorny and thornless shrubs.

\section{Results}

Experimental seed additions

The regeneration of both tree species was generally low. In the month with higher regeneration (May), out of a total of 6,000 fruits (seeds) of S. lorentzii sown in all experimental units, 259 seedlings were counted (4.3 seedlings 100 fruits $^{-1} \pm 0.72$; mean $\pm \mathrm{SE} ; n=60$ ). At the end of 
the experiment (March 2008), we recorded 91 seedlings in all experimental units (1.5 seedlings 100 fruits $^{-1} \pm 0.43$; mean $\pm \mathrm{SE} ; n=60$ ). Recruitment of A. quebracho-blanco was extremely low. Of a total of 6,000 seeds sown in all experimental units, only 6 seedlings emerged $(0.1 \%)$. These seedlings were found only under artificial shade treatments. Therefore, because of the low recruitment, no statistical analysis was performed for A. quebracho-blanco.

\section{Recruitment of S. lorentzii}

Greater seedling abundance of $S$. lorentzii was observed under artificial shade compared to the other two shade treatments. In general, exclusion of both livestock ( $L$ ratio $=4.5, d f=3, P=0.108$; Fig. 1a) and small vertebrates $(L$ ratio $=13.2, d f=2, P=0.001$; Fig. $1 \mathrm{~b})$ enhanced seedling abundance under artificial shade. The effect of exclusion of small vertebrates depended jointly on the date and exclusion of livestock ( $L$ ratio $=32.7, d f=6$, $P<0.001$; Fig. 2). Due to this 3-way interaction, assessing 2-way interactions among any of these three factors seems pointless. The positive effect of artificial shade on seedling abundance was, on average, low on the first date, higher on the second and third date, and intermediate on the last dates analyzed $(L$ ratio $=75.3, d f=16, P<0.001 ;$ Fig. 2$)$.

The trends in the average number of leaves per seedling were similar in almost all treatments to those found for the number of seedlings per 100 fruits. The only difference was that, under direct sunlight (where the number of seedlings was minimal), we found a greater number of leaves per seedling than in the other shade treatments, this difference increased when livestock and small native herbivores were excluded (Online Resource 3 and 4).

\section{Direct and indirect effects of shrubs}

Our design allowed us to disentangle the direct (positive, negative and net) and indirect effects of shrubs on S. lorentzii seedlings, and we found no significant net direct effects or indirect ones. Specifically, in the absence of domestic and native herbivores, there was a positive and direct effect of artificial shade on all dates but a negative and direct effect of shrubs by interference (with the same magnitude as the positive effect). Therefore, the net effect of shrubs was negligible (Fig. 3a). Indirectly, the effects of shrubs mediated by livestock and mediated by native vertebrates were also negligible at all dates (Fig. 3b).

Spatial association analysis

The observational study showed that the spatial association between saplings and shrubs depended on the presence of
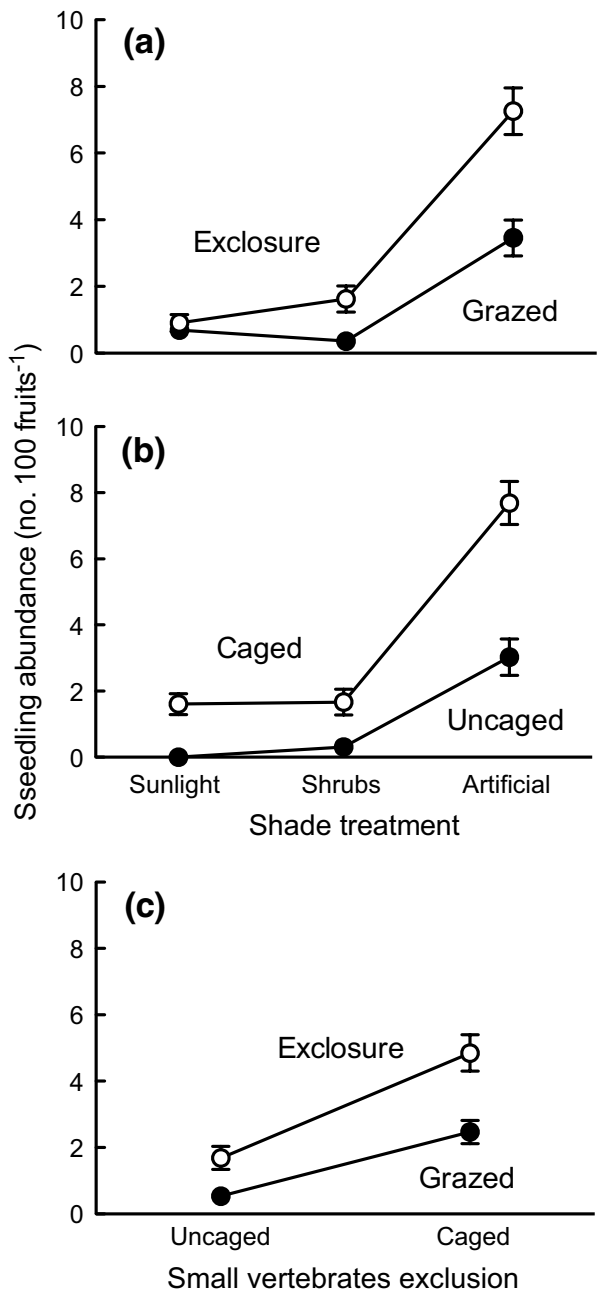

Fig. 1 Combined effects of the different experimental factors on Schinopsis lorentzii seedlings abundance in the study site in a dry Chaco forest, Argentina. Values are mean \pm SE. Effects of a shade treatments with respect to livestock exclusion treatments $(n=70)$, b shade treatments with respect to exclusion of small native herbivores $(n=70)$ and $\mathbf{c}$ exclusion treatments of native herbivores with respect to livestock exclusion treatments $(n=105)$

thorns on shrubs. Saplings of both tree species had a positive spatial association with thorny shrubs. On the other hand, no association was detected with thornless shrubs (Table 1).

\section{Discussion}

Contrary to our expectations, our results suggest that, in dry Chaco conditions (extremely high temperatures and irradiance), facilitation by thornless shrubs is not the dominant process driving regeneration of the target species. However, there are some indications (emerging from the associational analysis) that thorny shrubs may have net facilitative effects 


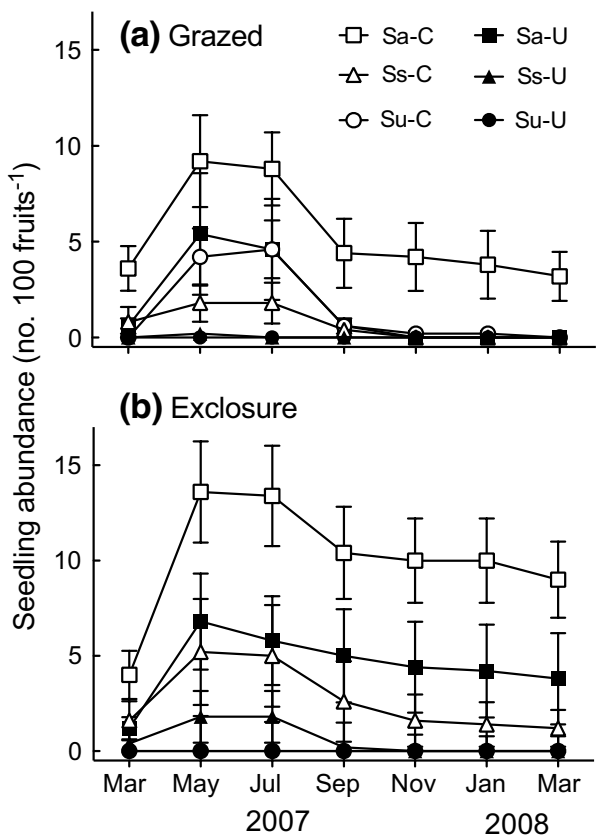

Fig. 2 Dynamics of abundance of Schinopsis lorentzii seedling (mean $\pm \mathrm{SE}$ ) in relation to shade treatments and native herbivores exclosure treatments, in a grazed plots and $\mathbf{b}$ exclosure plots $(n=5$ per treatment in each date). $C$ Caged, $U$ uncaged, $S s$ shade of $C a p-$ paris shrubs, $S a$ artificial shade, $S u$ sunlight

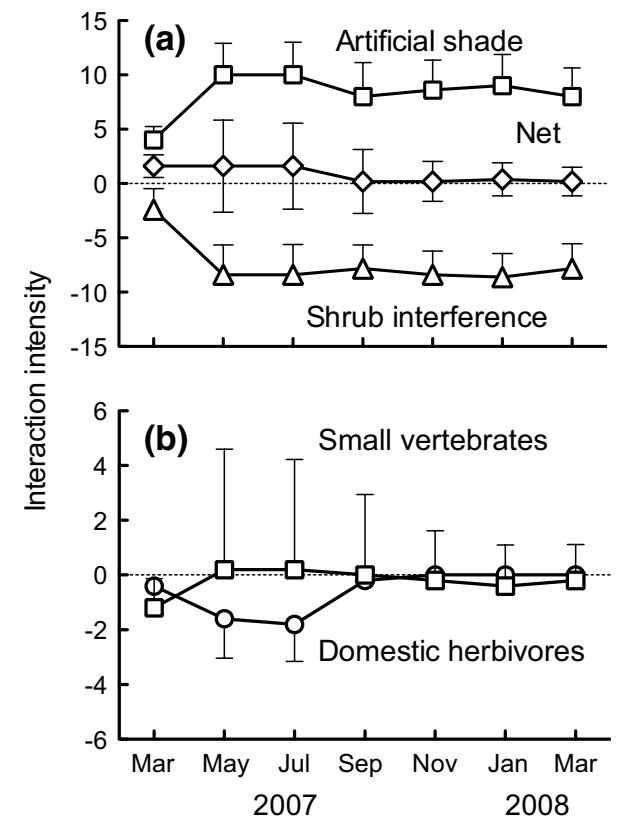

Fig. 3 Intensity of the interaction for cases of $\mathbf{a}$ direct and $\mathbf{b}$ indirect (mediated by livestock or by native herbivores) effects of thornless shrubs on Schinopsis lorentzii seedlings (means $+\mathrm{SE}, n=5$ ). The interaction intensity was quantified as the difference in the mean number of seedlings between the two treatments. See text for treatment comparisons. Net net effects of shrubs, i.e., the difference between artificial shade effects (positive) and thornless shrub effects (negative)
Table 1 Association indexes $\left(X_{\mathrm{p}}\right)$ of Aspidisperma quebracho-blanco and Schinopsis lorenzii saplings with potential categories of nurse plants

\begin{tabular}{llllll}
\hline Shrub type & \multicolumn{2}{l}{ A. quebracho-blanco } & & \multicolumn{2}{l}{ S. lorentzii } \\
\cline { 2 - 3 } \cline { 6 - 7 } & $X_{\mathrm{p}}$ & $P$ & & $X_{\mathrm{p}}$ & $P$ \\
\hline Thorny & 0.18 & 0.002 & & 0.16 & 0.003 \\
Thornless & 0.018 & 0.382 & & 0.066 & 0.170 \\
\hline
\end{tabular}

Significant $X_{\mathrm{p}}(P<0.05)$ indicate positive association between tree saplings and shrubs distributions

on recruitment. Our field experiment showed that the rate of seed germination and early establishment of $S$. lorentzii were very low and depended on the effect of artificial shade and the exclusion of livestock and native herbivores. The thornless shrubs used in the experiment (Capparis spp.) did not show either a direct positive net effect on early establishment of $S$. lorentzii or an indirect positive effect mediated by livestock as expected. Moreover, those shrubs did not show an indirect negative effect on regeneration.

In arid and semi-arid environments, abiotic stress is an important cause of death of seedlings, therefore shrubs are expected to increase the survival of seedlings through stress amelioration (Bertness and Callaway 1994; Flores and Jurado 2003; Barchuk et al. 2005; Michalet 2006; Brooker et al. 2008). In our study, shrubs significantly decreased incident light levels, and to the same levels as did the nylon shade cloth. However, the probable positive effect of shrub shade (because artificial shade resulted in significantly higher seedling abundance) was offset by other factors, resulting in no overall net effect on seedling establishment. The lack of an overall net positive effect of shrubs might be by other factors such as ground cover composition, allelopathy, and root competition, among others. Our experimental evidence is consistent with the results of the analysis of spatial patterns, because no positive association of S. lorenzii saplings with thornless shrubs was observed. Our findings contrast with those for a similar forest but with higher hydric stress (400 $\mathrm{mm}$ annual rainfall in the arid Chaco) where both thornless and thorny shrubs were found to facilitate regeneration of A. quebracho-blanco (Barchuk et al. 2005). These observations are consistent with the stress gradient hypothesis, which predicts a net balance toward positive interactions as the abiotic stress increases (Bertness and Callaway 1994; Maestre et al. 2009).

Contrary to what we predicted, Capparis spp. shrubs did not exert an indirect positive effect mediated by livestock. This result might be explained by the fact that the lowmedium palatability (Catan and Degano 2007) and branchness of Capparis spp. shrubs was not enough to deter livestock. This explanation is supported by the absence of spatial association found in our study between the saplings 
of both tree species and thornless shrubs (Capparis spp.). In contrast, thorny shrubs may offer refuge against herbivores, as we found a positive spatial association between thorny shrubs and tree saplings. Similar results have been found in other arid environments (McAuliffe 1984, 1986; Anthelme and Michalet 2009), suggesting that grazing refuges offered by thorny shrubs may be an important factor in determining the success of plant regeneration. Similarly, tree saplings of A. quebracho-blanco in the arid Chaco in Argentina (400 mm annual rainfall) showed a spatial positive association with a thorny species (Mimozyganthus carinatus, Fabaceae), and especially with evergreen shrubs, suggesting that the leaf lifespan of shrubs is also an important characteristic to mitigate negative effects of excessive radiation and high temperatures typical of the arid Chaco (Barchuk et al. 2008), but not in the semiarid portion of the Chaco forest.

We did not find evidence that shrubs have a negative indirect effect, mediated by native herbivores, on regeneration. This might arise if shrubs offered shelter to native herbivores, resulting in higher herbivory rates on tree seedlings growing under the canopy of the shrubs than away from them (Chaneton et al. 2010; Orrock et al. 2010). This interaction has been observed in patchy environments (Holt 1984), which might be the explanation for the lack of evidence in the dry Chaco forest, whose understory does not show patchy distributions as in other arid and semi-arid environments.

Although the analysis of responses of A. quebrachoblanco were not possible because of the high mortality, the fact that most of the few seedlings that emerged were under artificial shade protected from livestock and native herbivores (conditions that improved the establishment of $S$. lorentzii), lead us to propose that both tree species likely respond similarly to the treatments assessed. However, this needs to be tested in future experiments.

Even when livestock were excluded, we found that $S$. lorentzii did not recruit under the natural conditions of the study area at the end of the experiment (i.e., under shrubs or in direct sunlight, and in the presence of native herbivores which seem to play a key role in decreasing seedling recruitment of this species). In this scenario of low natural regeneration in natural conditions, it is necessary to propose management guidelines. According to the results of the field experiment, protecting $S$. lorentzii seedlings from herbivory and providing better shade conditions is recommended in order to increase the success in the early establishment of this key tree species in the Chaco forest.

In summary, our study contributes to a better understanding of the ecological mechanisms involved in the regeneration of tree species in dry forests. Our observational and manipulative study suggests that facilitation processes may depend on the presence of plant structures that deter herbivores, other than branching. We propose a possible positive net effect of thorny shrubs on tree regeneration, but thornless shrubs do not exert any net effect on tree regeneration due to complementary effects between the effects of shade (positive) and interference (negative). Indirect effects of thornless shrubs (both positive and negative) were negligible in this dry forest. The trends in the interactions assessed in the dry Chaco forest could be useful to test the relative importance of direct and indirect effects of thorn and thornless shrubs in other dry forests.

Author contribution statement A.T., A.H.B. and C.E.T. conceived and designed the experiments. A.T., S.C. and F.M. performed the experiments. A.T., A.H.B. and L.A.G. analyzed the data. A.T., A.H.B., L.A.G., C.E.T., wrote the manuscript; S.C. and F.M. provided editorial advice.

Acknowledgments This paper was made possible due to the support of the Consejo de Investigación de la Universidad Nacional de Salta (CIUNSa), Consejo Nacional de Investigaciones Científicas y Técnicas (CONICET) and to the grants provided by The Rufford Small Grant Foundation. We also would like to thank the National Parks Administration, which allowed us to conduct our research. Feedback from P. Graff, T. Kitzberger, K. Clark and L. Branch on an early version of this work and comments from J. Armesto, Katherine Gross and two anonymous reviewers greatly improved the manuscript. Finally, we would like to thank E. Tordoya, C. Yáñez, A. Gorosito and Y. Bonduri for field assistance and to C. Moraga, K. Clark, L. Branch, D.L. Miller and M. Thetford for English translation of the manuscript. The experiments comply with the current laws of Argentina in which the experiments were performed.

\section{References}

Alzugaray C, Carnevale NJ, Salinas AR, Pioli R (2007) Factores bioticos y abioticos que afectan la calidad de las semillas de Schinopsis balansae Engl. y Aspidosperma quebracho-blanco Schltdl. Rev Iberoam Micol 24:142-147

Anthelme F, Michalet R (2009) Grass-to-tree facilitation in an arid grazed environment (Air mountains, Sahara). Basic Appl Ecol 10:437-446. doi:10.1016/j.baae.2008.10.008

Baraza E, Zamora R, Hodar JA (2006) Conditional outcomes in plant-herbivore interactions: neighbours matter. Oikos 113:148156. doi:10.1111/j.0030-1299.2006.14265.x

Barbosa P, Hines J, Kaplan I (2009) Associational resistance and associational susceptibility: having right or wrong neighbors. Annu Rev Ecol Evol Syst 40:1-20

Barchuk AH, Valiente-Banuet A, Diaz MP (2005) Effect of shrubs and seasonal variability of rainfall on the establishment of Aspidosperma quebracho-blanco in two edaphically contrasting environments. Austral Ecol 30:695-705. doi:10.1111/j.1442-9993.2005.01511.x

Barchuk AH, Iglesias MDR, Boetto MN (2008) Spatial association of Aspidosperma quebracho-blanco juveniles with shrubs and conspecific adults in the Arid Chaco, Argentina. Austral Ecol 33:775-783. doi:10.1111/j.1442-9993.2008.01846.x

Bates D, Maechler M, Bolker B (2012) lme4: Linear mixed-effects models using S4 classes. R package version 0.999999-0. http:// CRAN.R-project.org/package $=$ lme 4 
Bertness MD, Callaway R (1994) Positive interactions in communities. Trends Ecol Evol 9:191-193. doi:10.1016/0169-5347(94)90088-4

Boletta PE, Ravelo AC, Planchuelo AM, Grilli M (2006) Assessing deforestation in the Argentine Chaco. For Ecol Manag 228:108114. doi:10.1016/j.foreco.2006.02.045

Brooker RW, Maestre FT, Callaway RM et al (2008) Facilitation in plant communities: the past, the present, and the future. J Ecol 96:18-34. doi:10.1111/j.1365-2745.2007.01295.x

Caccia FD, Chaneton EJ, Kitzberger T (2009) Direct and indirect effects of understory bamboo shape tree regeneration niches in a mixed temperate forest. Oecologia 161:771-780. doi:10.1007/ s00442-009-1412-z

Callaway RM (1995) Positive interactions among plants. Bot Rev 61:306-349. doi:10.1007/bf02912621

Callaway RM, Walker LR (1997) Competition and facilitation: a synthetic approach to interactions in plant communities. Ecology 78:1958-1965. doi: 10.1890/0012-9658(1997)078[1958:cafasa]2 $.0 . \mathrm{co} ; 2$

Carrillo-Garcia A, Bashan Y, Bethlenfalvay GJ (2000) Resourceisland soils and the survival of the giant cactus, cardon, of Baja California Sur. Plant Soil 218:207-214. doi:10.102 3/a:1014953028163

Catan A, Degano CAM (2007) Composición botánica de la dieta de caprinos en un bosque del Chaco semiárido (Argentina). Quebracho 14:15-22

Chaneton EJ, Mazia CN, Kitzberger T (2010) Facilitation vs. apparent competition: insect herbivory alters tree seedling recruitment under nurse shrubs in a steppe-woodland ecotone. J Ecol 98:488497. doi:10.1111/j.1365-2745.2009.01631.x

Cuesta B, Villar-Salvador P, Puertolas J et al (2010) Facilitation of Quercus ilex in Mediterranean shrubland is explained by both direct and indirect interactions mediated by herbs. J Ecol 98:687696. doi:10.1111/j.1365-2745.2010.01655.x

Dinerstein E, Olson DM, Graham DJ et al (1995) A conservation assessment of the terrestrial ecoregions of Latin America and the Caribbean. WWF-The World Bank, Washington, DC

Flores J, Jurado E (2003) Are nurse-protege interactions more common among plants from arid environments? J Veg Sci 14:911916. doi:10.1111/j.1654-1103.2003.tb02225.x

Gasparri NI, Grau HR (2009) Deforestation and fragmentation of Chaco dry forest in NW Argentina (1972-2007). For Ecol Manag 258:913-921. doi:10.1016/j.foreco.2009.02.024

Gomez-Aparicio L, Zamora R, Castro J, Hodar JA (2008) Facilitation of tree saplings by nurse plants: microhabitat amelioration or protection against herbivores? J Veg Sci 19:161-172. doi: 10.3170/2007-8-18347

Graff P, Aguiar MR (2011) Testing the role of biotic stress in the stress gradient hypothesis. Processes and patterns in arid rangelands. Oikos 120:1023-1030. doi:10.1111/j.1600-0706.2010.19059.x

Graff P, Aguiar MR, Chaneton EJ (2007) Shifts in positive and negative plant interactions along a grazing intensity gradient. Ecology 88:188-199. doi:10.1890/0012-9658(2007)88[188:sipanp]2.0.co;2

Harper JL (1977) Population biology of plants. Academic, London

Holmgren M, Scheffer M, Huston MA (1997) The interplay of facilitation and competition in plant communities. Ecology 78:19661975. doi:10.1890/0012-9658(1997)078[1966:TIOFAC]2.0.CO;2

Holt RD (1984) Spatial heterogeneity, indirect interactions, and the coexistence of prey species. Am Nat 124:377-406. doi:10.1086/284280

Jensen AM, Lof M, Gardiner ES (2011) Effects of above- and belowground competition from shrubs on photosynthesis, transpiration and growth in Quercus robur L. seedlings. Environ Exp Bot 71:367-375. doi:10.1016/j.envexpbot.2011.02.005
Kitajima K, Fenner M (2000) Ecology of seedling regeneration. CABI, Wallingford

Maestre FT, Bautista S, Cortina J (2003) Positive, negative, and net effects in grass-shrub interactions in mediterranean semiarid grasslands. Ecology 84:3186-3197. doi:10.1890/02-0635

Maestre FT, Callaway RM, Valladares F, Lortie CJ (2009) Refining the stress-gradient hypothesis for competition and facilitation in plant communities. J Ecol 97:199-205. doi:10.1111/j.1365-2745.2008.01476.x

McAuliffe JR (1984) Sahuaro-nurse tree associations in the Sonoran Desert: competitive effects of sahuaros. Oecologia 64:319-321. doi:10.1007/bf00379128

McAuliffe JR (1986) Herbivore-limited establishment of a sonoran desert tree, Cercidium microphyllum. Ecology 67:276-280. doi: $10.2307 / 1938533$

Michalet R (2006) Is facilitation in arid environments the result of direct or complex interactions? Commentary. New Phytol 169:36. doi:10.1111/j.1468-8137.2006.01617.x

Orrock JL, Holt RD, Baskett ML (2010) Refuge-mediated apparent competition in plant-consumer interactions. Ecol Lett 13:11-20. doi:10.1111/j.1461-0248.2009.01412.x

Paez SA, Marco DE (2000) Seedling habitat structure in dry Chaco forest (Argentina). J Arid Environ 46:57-68. doi:10.1006/ jare. 2000.0648

Peguero G, Lanuza OR, Save R, Espelta JM (2012) Allelopathic potential of the neotropical dry-forest tree Acacia pennatula Benth: inhibition of seedling establishment exceeds facilitation under tree canopies. Plant Ecol 213:1945-1953. doi:10.1007/s11258-011-0014-0

Perry JN (1998) Measures of spatial pattern for counts. Ecology 79:1008-1017. doi:10.1890/0012-9658(1998)079[1008:mospfc] 2.0.co;2

Perry JN, Bell ED, Smith RH, Woiwod IP (1996) SADIE: software to measure and model spatial pattern. Asp Appl Biol 46:95-102

Perry JN, Winder L, Holland JM, Alston RD (1999) Red-blue plots for detecting clusters in count data. Ecol Lett 2:106-113. doi:10.1046/j.1461-0248.1999.22057.x

Portillo-Quintero CA, Sanchez-Azofeifa GA (2010) Extent and conservation of tropical dry forests in the Americas. Biol Conserv 143:144-155. doi:10.1016/j.biocon.2009.09.020

Prado DE (1993) What is the Gran Chaco vegetation in South America? I. A review: contribution to the study of flora and vegetation of the Chaco, V. Candollea 48:145-172

Prevosto B, Monnier Y, Ripert C, Fernandez C (2012) To what extent do time, species identity and selected plant response variables influence woody plant interactions? J Appl Ecol 49:1344-1355. doi:10.1111/jpe. 12000

R Development Core Team (2012) R: a language and environment for statistical computing, Vienna. http://www.r-project.org

Ridenour WM, Callaway RM (2001) The relative importance of allelopathy in interference: the effects of an invasive weed on a native bunchgrass. Oecologia 126:444-450. doi:10.1007/s004420000533

Seghezzo L, Volante JN, Paruelo JM et al (2011) Native forests and agriculture in Salta (Argentina): conflicting visions of development. J Environ Dev 20:251-277. doi:10.1177/1070496511416915

Smit C, Den Ouden JAN, Muller-Scharer H (2006) Unpalatable plants facilitate tree sapling survival in wooded pastures. J Appl Ecol 43:305-312. doi:10.1111/j.1365-2664.2006.01147.x

Tálamo A, Caziani SM (2003) Variation in woody vegetation among sites with different disturbance histories in the Argentine Chaco. For Ecol Manag 184:79-92. doi:10.1016/s0378-1127(03)00150-6

Zuur FL, Ieno AF, Walker NJ et al (2009) Mixed effects models and extensions in ecology with R. Springer, New York 